\title{
Waardenburg syndrome
}

\author{
Andrew P Read, Valerie E Newton
}

\begin{abstract}
Auditory-pigmentary syndromes are caused by physical absence of melanocytes from the skin, hair, eyes, or the stria vascularis of the cochlea. Dominantly inherited examples with patchy depigmentation are usually labelled Waardenburg syndrome (WS). Type I WS, characterised by dystopia canthorum, is caused by loss of function mutations in the PAX3 gene. Type III WS (KleinWaardenburg syndrome, with abnormalities of the arms) is an extreme presentation of type I; some but not all patients are homozygotes. Type IV WS (Shah-Waardenburg syndrome with Hirschsprung disease) can be caused by mutations in the genes for endothelin-3 or one of its receptors, EDNRB. Type II WS is a heterogeneous group, about $15 \%$ of whom are heterozygous for mutations in the MITF (microphthalmia associated transcription factor) gene. All these forms show marked variability even within families, and at present it is not possible to predict the severity, even when a mutation is detected. Characterising the genes is helping to unravel important developmental pathways in the neural crest and its derivatives.

( Med Genet 1997;34:656-665)
\end{abstract}

Keywords: Waardenburg syndrome; auditorypigmentary syndromes

\section{History}

On 14 December 1947 the Dutch ophthalmologist and geneticist Petrus J Waardenburg presented a deaf-mute man with "dystopia punctorum lacrimarum, blepharophimosis and partial iris atrophy" to a meeting of the Dutch Ophthalmological Society. ${ }^{1}$ The patient had blue eyes but was bald, and Waardenburg did not at the time make the connection between hearing loss, white forelock, unusual eye colour, and dystopia canthorum. He mentioned a report of twins with the same eye abnormality who were "coincidentally" also deaf-mute. The following year, while he was visiting Geneva, David Klein showed him a 10 year old girl with a remarkably severe auditory-pigmentary syndrome who also had dystopia canthorum. Realising that coincidences were multiplying, Waardenburg was prompted to undertake a systematic search among 1050 inmates of five Dutch institutions for the deaf.

Waardenburg's results, published in a huge paper $^{2}$ in the American fournal of Human Genetics in 1951, defined the syndrome now named type I Waardenburg syndrome (WS1). He characterised the syndrome as autosomal dominant with very high penetrance $(159 / 161)$ of dystopia but reduced penetrance of all other features. He appears to have taken little interest in the patients who did not have dystopia canthorum (he noted seven people with heterochromia or isochromic hypoplastic irides, but without dystopia, whom he did not investigate further). It was not until 1971 that $\mathrm{Arias}^{3}$ drew attention to the existence of a separate division of the syndrome, which he named type II Waardenburg syndrome (WS2). WS2 has identical auditory and pigmentary features to WS1 but lacks dystopia canthorum. Two of Waardenburg's original families had this variant, but both were so small that Waardenburg had overlooked the familial "non-penetrance" of dystopia.

Klein's patient was very different from those in Waardenburg's families. As well as showing the usual features of Waardenburg syndrome type I to an exceptional degree, she also suffered from a severe musculoskeletal syndrome resembling amyoplasia. At first, Waardenburg speculated that perhaps she was homozygous for the gene mutated in his syndrome. Later he evidently came to feel that Klein's patient represented some different clinical entity, a view that Klein did not appreciate. ${ }^{4}$ Over the years a small number of other patients have been described who show similar features to Klein's patient, but in milder form. WS with musculoskeletal abnormalities has been called type III WS, KleinWaardenburg syndrome, or WS3. Already in $1983 \mathrm{Klein}^{4}$ suggested that this was a variant presentation of WS1.

In 1981, Shah et at described 12 babies with Hirschsprung's disease, white forelocks, and white eyelashes, born to five families in Bombay. What, if any, relation these babies had to Waardenburg syndrome is not clear. Dystopia was absent, hearing was not tested because all babies died in the neonatal period, and the 
Table 1 The four types of Waardenburg syndrome

\begin{tabular}{|c|c|c|c|c|}
\hline Type & $M I M$ & Inheritance & Distinguishing feature & Comments \\
\hline I & 193500 & $\mathrm{AD}$ & Dystopia canthorum W>1.95 & Nearly all have PAX 3 mutations \\
\hline II & 193510 & $\mathrm{AD}$ & No dystopia & $\begin{array}{l}\text { Heterogeneous; } 15 \% \text { have MITF } \\
\text { mutations }\end{array}$ \\
\hline III (Klein-Waardenburg) & 148820 & $\begin{array}{l}\mathrm{AD} \text { (most cases } \\
\text { sporadic) }\end{array}$ & $\begin{array}{l}\text { Hypoplasia of limb muscles; } \\
\text { contractures of elbows, fingers }\end{array}$ & $\begin{array}{l}\text { Variant presentation of WS1; mostly } \\
\text { PAX3 heterozygotes; some may be } \\
\text { homozygotes }\end{array}$ \\
\hline IV (Shah-Waardenburg) & 277580 & Mostly AR & Hirschsprung's disease & $\begin{array}{l}\text { Heterogeneous; includes } \\
\text { homozygotes for EDN3 or EDNRB } \\
\text { mutations }\end{array}$ \\
\hline
\end{tabular}

pigmentary disorder of the irides was reported as "isochromia irides, light brown irides with mosaic pattern...a common inherited condition in our population". However, the presumed recessive combination of pigmentary disturbance and Hirschsprung's disease has been called Shah-Waardenburg syndrome, type IV Waardenburg syndrome, or WS4. Recent demonstration of mutations in endothelin-3 and its receptor (see below) have allowed a new and more concrete definition of WS4.

\section{Clinical features of Waardenburg syndrome types I and II}

Table 1 summarises the four clinical types of Waardenburg syndrome and formal diagnostic criteria are shown in table 2 . Whereas WS1 defines a specific genetic entity, the clinical definition of WS2 is arbitrary, covering any auditory-pigmentary syndrome that does not clearly belong somewhere else. The label WS2 undoubtedly covers a heterogeneous collection of melanocyte defects. Apart from dystopia canthorum, all features of WS1 and WS2 show

Table 2 Diagnostic criteria for Waardenburg syndrome types $I$ and $I I$

Diagnostic criteria for WS1 have been proposed by the Waardenburg Consortium. ${ }^{16}$ In brief, to be counted as affected a person must have two major or one major plus two minor criteria, from the following list:

Major criteria

Congenital sensorineural hearing loss

Pigmentary disturbances of iris (a) complete heterochromia iridium: two eyes of different colour; (b) partial or segmenta heterochromia: segments of blue or brown pigmentation in one or both eyes; or (c) hypoplastic blue eyes: characteristic brilliant blue in both eyes

Hair hypopigmentation: white forelock

Dystopia canthorum: $\mathrm{W}>1.95$ averaged over affected family members (note that this was modified from the original proposal of $W>2.07$ in the light of experience)

Affected first degree relative

Minor criteria

Congenital leucoderma: several areas of hypopigmented skin Synophyrys or medial eyebrow flare

Broad and high nasal root

Hypoplasia of alae nasi

Premature greying of hair: scalp hair predominantly white before age 30

Criteria for WS2 were suggested by Lui et al. ${ }^{6}$ These authors recommended that two major features should be present to make the diagnosis of WS2. The major features are as in the list above, except for the exclusion of dystopia canthorum and inclusion of premature greying marked interfamilial and intrafamilial variability. Table 3 shows the penetrance of the various features in a series of WS patients reported by Liu et al, ${ }^{6}$ from our own observations, and from published reports. The same pigmentation defects appear in WS1 and WS2, but with different frequency. ${ }^{6}$ The higher reported incidence of hearing loss in WS2 compared to WS1 is probably mainly a consequence of diagnostic requirements: without dystopia canthorum as a guide, patients need to show more auditory-pigmentary features to be classified as affected. Fig 1 shows typical facial appearances of WS1 and WS2.

\section{INCIDENCE AND PREVALENCE}

Waardenburg ${ }^{2}$ estimated the prevalence of his syndrome to be $1 / 42000$ of the population and $1.43 \%$ of the congenitally deaf. Fraser ${ }^{7}$ found a prevalence of 2.12-3.01/100 000 in his school study of 2355 deaf children, and estimated a prevalence of 1.44-2.05/100 000 in the general population. WS1 and WS2, as defined by the diagnostic criteria in table 2 , are about equally common. In addition there are many families ascertained through a proband with hearing loss, in which one or more relatives have single features of WS2, without anybody satisfying the full diagnostic criteria. Without molecular data it is impossible to say whether or not these families should be added to the figures for WS2. The mutation rate has been estimated as $0.4 / 100000$ gametes $^{2}$ or $0.39 / 100000$ gametes. $^{7}$

\section{DYSTOPIA CANTHORUM}

Dystopia canthorum is the most penetrant feature of WS1, being present in $99 \%$ of those affected. ${ }^{8}$ Dystopia presents with the appearance of blepharophimosis and with fusion of the inner eyelids medially leading to a reduction in the medial sclerae (fig 1). The inferior lachrymal ducts are displaced laterally, with the punctae opposite the cornea. Not only the inner canthal, but also the interpupillary and outer canthal distances are greater than normal, indicating a degree of hypertelorism.

In the majority of affected subjects dystopia is readily recognised, but our experience shows that clinical impression is not altogether reliable. Subjects with WS2 risk being misdiagnosed as WS1 if there is mild hypertelorism. It is much better to rely on a biometric index. The W index (fig 2) is the best of several broadly equivalent indices ${ }^{9}$ (the bizarre numbers in the formula come from a discriminant analysis). Such indices are based upon the inner canthal, interpupillary, and outer canthal 
Table 3 Penetrance (\%) of clinical features of type I and type II Waardenburg syndrome. Data from Liu et al (where references to published cases are given)

\begin{tabular}{lllllllllll}
\hline Type & Source & \multirow{2}{*}{ No } & \multirow{2}{*}{ SNHL } & HetI & HypE & WF & EG & Skin & HNR & Eyb \\
\hline WS1 & Liu et al & 60 & 58 & 15 & 15 & 48 & 38 & 36 & 100 & 63 \\
& Other reports & 210 & 57 & 31 & 18 & 43 & 23 & 30 & 52 & 70 \\
WS2 & Liu et at & 81 & 78 & 42 & 3 & 23 & 30 & 5 & 0 & 7 \\
& Other reports & 43 & 77 & 54 & 23 & 16 & 14 & 12 & 14 & 7 \\
\hline
\end{tabular}

SNHL=sensorineural hearing loss, HetI= heterochromia irides, HypE=hypoplastic blue eyes, $\mathrm{WF}=$ white forelock, $E G=$ early greying, Skin=white skin patches, HNR=high nasal root, $\mathrm{Eyb}=$ medial eyebrow flare.
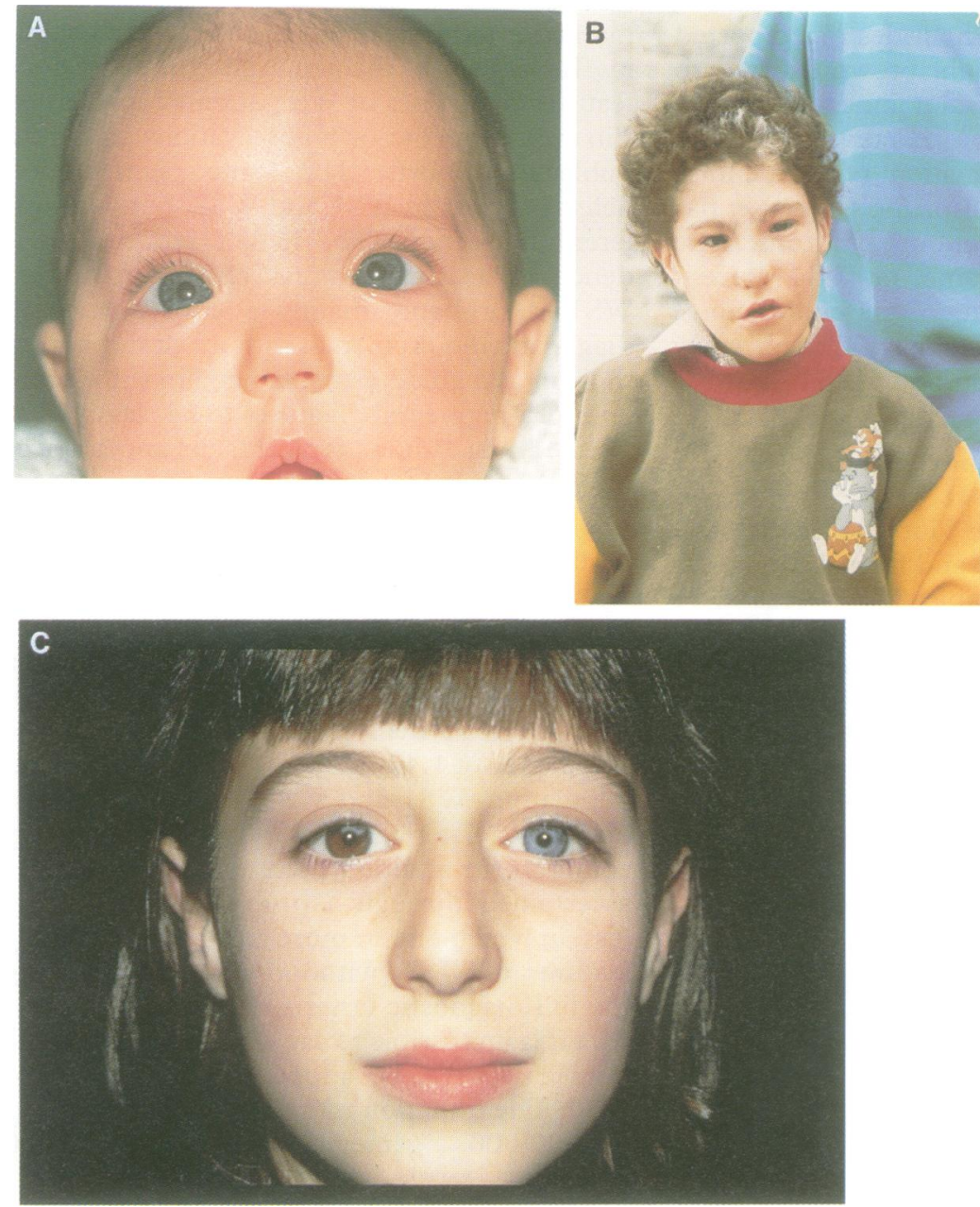

Figure 1 Facial appearance of Waardenburg syndrome. (A) Type I WS. Note dystopia canthorum. (B) Type I WS. Typical features include profound hearing loss, dystopia canthorum. (B) Type I WS. Typical features include profound hearing loss, dystopia
canthorum, pale blue eyes, white forelock, and white eyelashes on the left. This boy has a canthorum, pale blue eyes, white forelock, and white eyelashes on the left. This boy has a
deletion of 7-8 Mb of DNA including the entire PAX3 gene. Other clinical features (mental retardation, growth retardation) are attributed to deletion of other genes. (C) Type II WS caused by a splice site mutation in the MITF gene. Note eye colour, with blue left eye and brown right eye with a sharply demarcated radial blue segment; note normal build of face with no dystopia canthorum. She has mild unilateral hearing loss. Other affected relatives with the same mutation show white forelock, early greying, and varying degrees of hearing loss.

distances. Indices based on these three measurements are more reliable than those based upon two measures alone, although if there is strabismus the interpupillary distance cannot be used. The indices depend upon the relationship between the measurements rather than absolute measures, and so should be unaffected by age, race, or sex.

Fig 3 shows the justification for placing such emphasis on dystopia. In this data set, every family with mean $W>1.95$ (averaged over all affected family members), but no family with mean $\mathrm{W}<1.95$, shows evidence of PAX3 involvement from linkage or mutation analysis. One family had a W value between 1.95 and
2.07, the threshold first adopted by the Waardenburg Consortium, and was published as a type II family with a PAX 3 mutation. ${ }^{10}$ The data in fig 3 suggest that a threshold of 1.95, averaged across all affected family members, gives the best distinction, and reclassifies this family as WS1. As the figure shows, the eye measurements in persons with WS1 and WS2 can overlap, so the threshold cannot be taken as absolute, but it has proven a very useful guide. Its practical value is as a guide to whether or not it is worth asking the laboratory to look for a PAX3 mutation (see below).

\section{OTHER FACIAL FEATURES}

A broad, high nasal root, medial hypertrichosis and synophyrys, and hypoplasia of the alae nasi are features associated with dystopia canthorum in WS1 (table 3). Other facial features described include a patent metopic suture and square jaw. ${ }^{11}$ Strabismus may be more common with WS1 than normally. ${ }^{12}$

\section{EYE COLOUR}

Iris heterochromia may be complete or partial. In complete heterochromia each iris is a different colour, while in partial heterochromia the differently coloured area of the iris is sharply demarcated from the remainder and is usually, but not invariably, a radial segment (fig 1C). Partial heterochromia may be unilateral or bilateral and, if bilateral, may be symmetrical or asymmetrical. Partial heterochromia was found in $4.2 \%$ of subjects with WS1 and $27.5 \%$ of those with WS2 in our study. ${ }^{6}$

Hypoplastic blue irises are found where there is deficient iris stroma, and mainly in association with a severe or profound hearing loss. ${ }^{6}$ We found that hypoplastic blue irises were significantly more common in children with WS1 than WS2. The fundus is reported to show pigmentary changes that correspond to those found on the retina. ${ }^{12} 13$

\section{HAIR COLOUR}

A distinctive white forelock is usually described, but the forelock may be red or black. ${ }^{314}$ The site of the forelock is usually in the midline but it may be elsewhere on the head. It may vary in size from a few hairs to a clump of hair and, if present at birth, may persist or disappear only to reappear later, usually in the teens, when it is considered to represent early greying. ${ }^{15}$ Complete depigmentation of the hair may occur in the teens and the hair may be sparse and of poor quality. ${ }^{7}$ The premature greying signifying WS is defined by the Waardenburg Consortium as predominance of white hairs appearing before the age of 30 years with the white hairs appearing in the midline. ${ }^{16}$ Pigmentation defects can affect the eyebrows and eyelashes as well as scalp hair. $^{7}$

\section{SKIN SIGNS}

Hypopigmentation of the skin is congenital and may be found on the face, trunk, or limbs. It may be associated with an adjacent white forelock. Hyperpigmentation has also been described ${ }^{11}$ and this may develop after birth in 


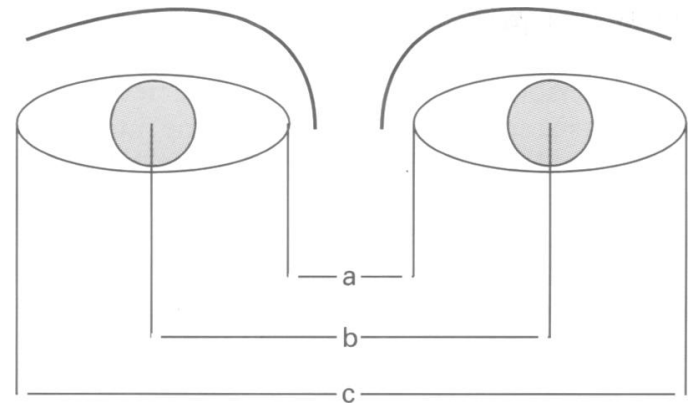

Figure 2 Diagnosis of dystopia canthorum. To calculate the $W$ index: (1) Measure $a, b, c$ in $\mathrm{mm}$ using a rigid ruler held against the face. (2) Calculate

$X=(2 a-0.2119 c-3.909) / c$. (3) Calculate

$Y=(2 a-0.2479 b-3.909) / b$. (4) Calculate $W=X+Y+a / b$ $W S$ type $I$ is diagnosed if the average $W$ of all affected

family members is 1.95 or more.

a previously hypopigmented area. Arias ${ }^{3}$ noted that hypopigmented areas frequently had hyperpigmented borders. If depigmented patches are extensive, piebaldism (owing to mutation in the KIT gene) should be suspected, especially if the patient has normal hearing.

HEARING

The hearing loss in Waardenburg syndrome is sensorineural, congenital, and usually nonprogressive. It may be unilateral or bilateral and can vary in degree from slight to profound. Hageman and Delleman ${ }^{17}$ reported that $25 \%$ of subjects with WS1 and $50 \%$ of those with WS2 had a bilateral sensorineural hearing loss. Newton ${ }^{18}$ found that the penetrance of sensorineural hearing loss varied from $69 \%$ in WS1 to $87 \%$ in WS2, after omitting the probands (who had been ascertained through their hearing loss). Variation between families was high.

A profound bilateral loss is the commonest degree of hearing loss in both types, particularly in type I. Unusual audiogram shapes

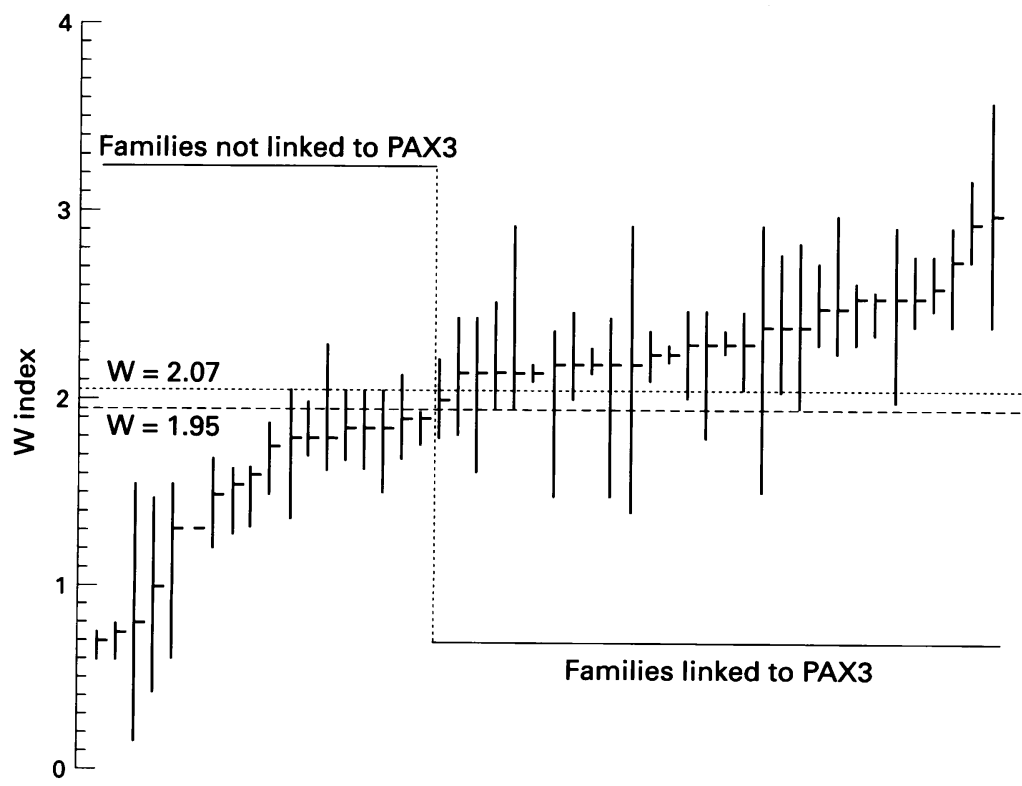

Figure 3 Dystopia canthorum: mean and range of $W$ values among affected people in 48 $W S$ families studied by the Waardenburg Consortium. The horizontal dotted lines show
proposed thresholds of $W=1.95$ or $W=2.07$ for distinguishing WS1 and WS2. Note that all families showing evidence of PAX3 involvement have average $W>1.95$, but not all have W>2.07. Redrawn from Farrer et al, Am $\mathcal{F}$ Hum Genet 1994;55:728-37 with permission. include low frequency and $U$ shaped losses, bilateral or unilateral, and sometimes a combination of a low frequency sensorineural hearing loss in one ear and a profound loss in the other.

Radiological investigation of the auditory system has indicated a normal temporal bone or dysplasia of the lateral semicircular canal associated with a normal bony cochlea. ${ }^{19}$ The histological appearance of one temporal bone studied by Fisch $^{11}$ was consistent with the auditory features of type I being caused by a cochleosaccular degeneration. Cochleosaccular degeneration and a complete absence of pigmentation was reported at necropsy in the inner ears of a 3 year old child with WS4. She had extensive skin depigmentation, bilateral profound hearing loss and aganglionic megacolcon, but not dystopia canthorum. ${ }^{74}$

\section{Other associated conditions}

A long list of other conditions have been reported in association with Waardenburg syndrome. ${ }^{20}$ It is difficult to disentangle to what extent these additional conditions are true rare manifestations of WS (type I or II), coincidental findings, or features of other neurocristopathies that are really separate syndromes. WS1 carries a small but definite risk of spina bifida $^{20}{ }^{21}$ and may occasionally be associated with Sprengel's shoulder ${ }^{7}$ (unpublished observations) and with cleft lip/palate. ${ }^{22}$

Hirschsprung disease (HSCR) is unquestionably associated with Waardenburg syndrome in WS4, which as described below is recessive and caused by mutations in the EDN3 and EDNRB genes. Whether there is also an association with other forms of Waardenburg syndrome is less clear. Most reports of WS-HSCR patients date from before the distinction was made between WS1 and WS2. One might expect WS1, as a neurocristopathy, to be the form associated with HSCR, but in fact any association that may exist of WS with HSCR is with type II WS. We are aware of only a single case of HSCR among the hundreds of WS1 patients with proven PAX3 mutations (R Ramesar, personal communication).

\section{Homozygous Waardenburg syndrome}

In view of the frequency of deaf-deaf marriages, WS homozygotes are likely to be conceived from time to time. Mouse models (see below) suggest that WS1 or WS2 homozygotes are likely to be very much more severely affected than heterozygotes, and this is a point to be borne in mind in genetic counselling. Double heterozygosity (for example, WS1WS2) is probably much less risky, although this view is not based on adequate data.

Two cases of homozygosity for WS1 have been described. Zlotogora et a ${ }^{23}$ described and illustrated a child with severe hypopigmentation, profound congenital hearing loss, and contractures of the forearms, born to a consanguineous Israeli Arab family. Both parents have typical WS1, and the child is homozygous for the PAX3 mutation S84F. The physical picture is strikingly reminiscent of Klein's original WS3 patient. Surprisingly, there is no neural 
tube defect, although in the Splotch mouse model homozygotes have lethal neural tube defects. Aymé and Philip ${ }^{24}$ described a fetus that was the product of brother-sister incest in a French Gypsy family with typical WS1. The pregnancy was terminated because of anencephaly diagnosed on scan; the fetus had major abnormalities very reminiscent of homozygous $S p$ mouse embryos, including severe contractures and webbing of the limbs. No material was available from the fetus, but we have found a PAX3 mutation N269L in a heterozygous member of the family ( $M$ Tassabehji, A P Read, unpublished data). This mutation is typical of those found in WS1.

Hultén et $a l^{5}$ described a profoundly deaf and severely depigmented child born to first cousin parents who both had white forelocks and white skin patches but normal hearing. The child might have been a WS2 homozygote, although homozygosity for piebaldism (KIT mutation) is perhaps more likely.

\section{The neural crest in auditory-pigmentary syndromes}

The association of hearing loss and pigmentary abnormalities has long been known in a variety of mammals. ${ }^{26}$ In his Origin of Species, Charles Darwin asked "What can be more singular than the relation between blue eyes and deafness in cats?" In all these auditory-pigmentary syndromes the underlying cause of the hearing loss is a still unexplained requirement for melanocytes in the stria vascularis of the cochlea. ${ }^{27}$ There is no requirement for melanin (albinos have normal hearing), but in the absence of melanocytes the stria is abnormally thin, no endocochlear potential is generated, and later in development Reissner's membrane collapses leading to destruction of the organ of Corti. ${ }^{26}{ }^{27}$ Thus auditory-pigmentary syndromes are caused by a physical absence of melanocytes which may affect skin, hair, eyes, or the stria vascularis. Usually the melanocyte deficiency is patchy, but alternatively a general dilution of pigmentation may be seen. In man, hearing loss with uniform dilution of pigmentation is usually described as Tietz-Smith syndrome (MIM 103500) rather than Waardenburg syndrome, but in both man and mouse, different alleles of the $m i / \mathrm{MITF}$ gene can cause either spotty or uniformly diluted depigmentation (see below).

All melanocytes except those in the retina originate in the embryonic neural crest. Absence of melanocytes could be because of a failure of differentiation in the neural crest, a failure of melanoblasts to migrate, or a failure to terminally differentiate and survive in their final location. Countless genes must be involved in these processes, and so the genetics of auditory-pigmentary syndromes is likely to be complex. ${ }^{29}$ A distinction might be made between those syndromes where only melanocytes are involved and those where there is a broader malfunction of the embryonic neural crest. A condition affecting both skin and retinal melanocytes is likely to be melanocyte specific, since retinal melanocytes are not derived from the neural crest. In Waardenburg syn- drome, some WS2 may be melanocyte specific, whereas WS1 and the rare variants WS 3 and WS4 are neurocristopathies, involving the frontal bone, limb muscles, and enteric ganglia, respectively. All these extra tissues are neural crest derivatives.

PAX3 and Waardenburg syndrome type I Foy et $a l^{30}$ mapped WS1 to the distal long arm of chromosome 2 in 1990, using a clue provided by a Japanese patient with de novo WS1 and a chromosomal inversion inv(2)(q35q37.3). ${ }^{31}$ The marker showing linkage was ALPP, the placental alkaline phosphatase. ALPP was said ${ }^{32}$ to map to $2 \mathrm{q} 37$, but this was based on radiolabelled in situ hybridisation results which were not totally unambiguous. ALPP is a difficult marker to use for in situ hybridisation because distal $2 \mathrm{q}$ contains at least three highly homologous alkaline phosphatase loci, ALPP, ALPI, and ALPPL2, which all cross react. Physically, the WS1 gene must be located at one of the inversion breakpoints in the Japanese patient, that is, $2 \mathrm{q} 35$ or $2 \mathrm{q} 37.3$. Fluorescent in situ hybridisation has now located the WS1 gene at $2 \mathrm{q} 35 .{ }^{33}$

On the basis of this map position, Foy et $a l^{30}$ suggested that WS1 might be homologous to the Splotch mouse mutant. This speculation proved correct when three groups identified PAX3 (originally called HuP2) and its mouse homologue Pax-3 as the gene mutated in WS1 and $S p .^{34.36}$

Our knowledge of PAX 3 expression mostly comes from studies of the mouse $\mathrm{Pax}-3$ gene, ${ }^{37-39}$ although preliminary studies in human embryos suggest a similar pattern. ${ }^{40}$ Summarising from the extensive studies of Gruss's group, ${ }^{38}$ no $\mathrm{Pax}-3$ transcripts were detected in any tissues of adult mouse, but transcripts were present in embryos from day 8 to day 17 , peaking at days 9 to 12 during neurulation. Transcripts were concentrated in neuroepithelium, in the dorsal part of the neural groove and in the recently closed neural tube. Pax-3 is expressed longitudinally down the length of the neural tube from the hindbrain, but only in mitotically active cells of the alar and roof plates, dorsal to the sulcus limitans. These cells are the source of the neural crest. Among neural crest derivatives, Pax-3 expression was seen in the spinal ganglia and some craniofacial cells (nasal process and some first and second branchial arch derivatives), but not in melanocytes, chromaffin granule cells, the developing heart, or sympathetic ganglia. In addition to neural tissue, segmented mesoderm also contained Pax-3 transcripts between 8.5 and 11 days of gestation. Onset of Pax-3 expression coincided closely with the division of presegmented mesoderm into discrete somites, and preceded formation of the dermomyotome and sclerotome; as the somites dissociate, Pax-3 expression is switched off. Note, however, that postnatal appearance or disappearance of a white forelock and greying in the teens or twenties have repeatedly been documented in WS1 families with defined PAX3 mutations, so not all effects of PAX3 are confined to neurulating embryos. Another site 
A

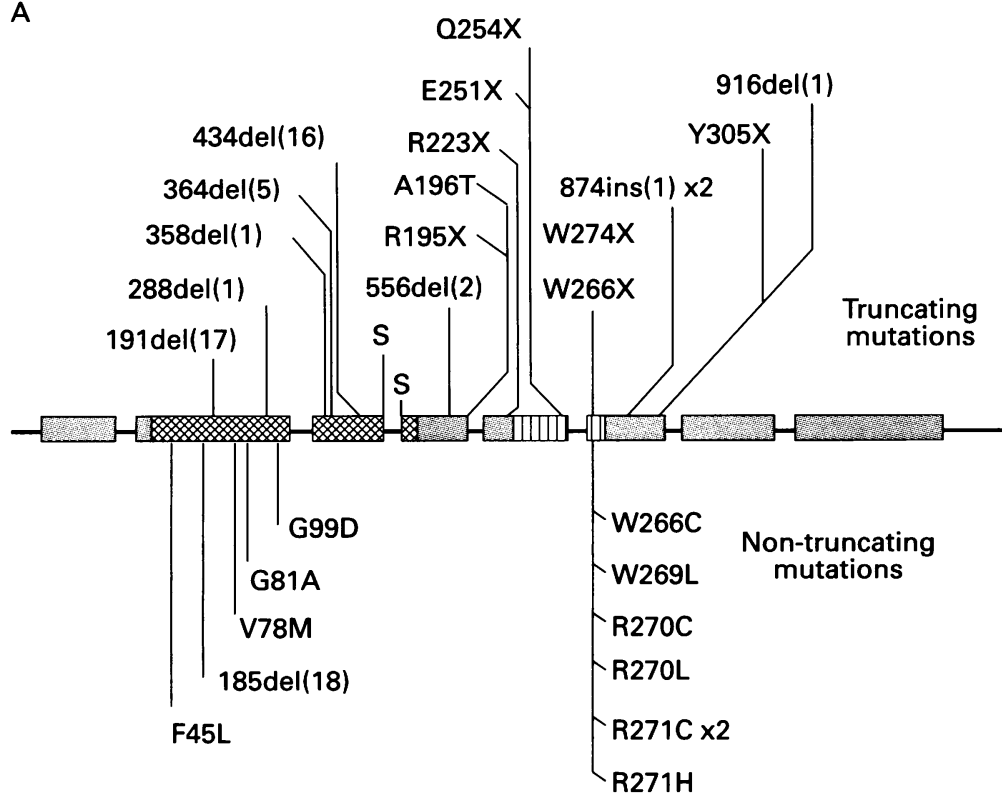

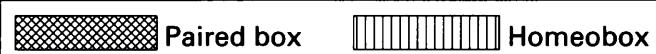

B

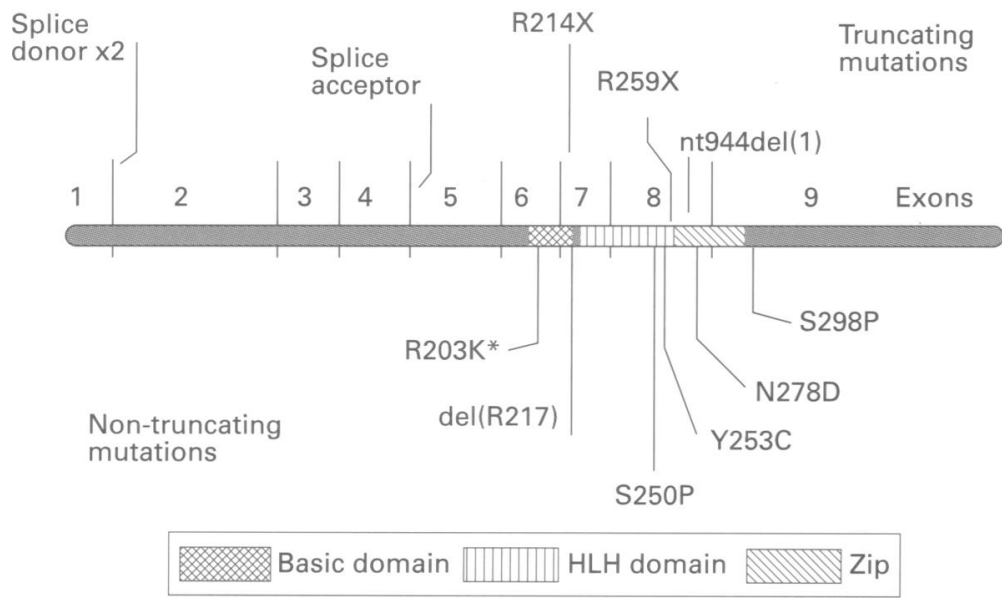

Figure 4 (A) PAX3 mutations in Waardenburg syndrome type I and III. The 434del(16) and 916del(1) mutations were found in patients with type III WS; all others were in type I. Note that non-truncating mutations are concentrated in the 5'part of the paired box and in the third helix of the homeobox, the two regions critical for protein $D N A$ recognition. The $A 196 T$ mutation is likely to affect splicing because it replaces the conserved $G$ at the $3^{\prime}$ end of exon $4^{47}$ (unpublished data from our laboratory); other groups have reported similar data. ${ }^{36}{ }^{48-53}(B)$ MITF mutations. The family with the del(R217) mutation (which is identical to the original microphthalmia mouse mutation) had Tietz-Smith rather than Waardenburg syndrome ${ }^{47}$; all other families had typical type II WS. The R203K mutation may be a neutral change: it was seen in the proband of a four generation family with typical WS2, but did not track with WS through the pedigree. ${ }^{47}$ Data from our laboratory ${ }^{47}$ (unpublished data), Nobokuni et al (R214X, R259X), ${ }^{64}$ and Morell et al (944del(1)).

of expression was the undifferentiated mesenchyme of the limb buds, ${ }^{41}$ explaining the phenotype of WS3.

PAX 3 encodes a DNA binding transcription factor, one of a family of nine human PAX proteins defined by the presence of a 128 amino acid paired domain. The prototype is the Drosophila paired (prd) gene. PAX3, PAX6, and PAX7 proteins additionally contain a homeodomain. An important research goal is to iden-

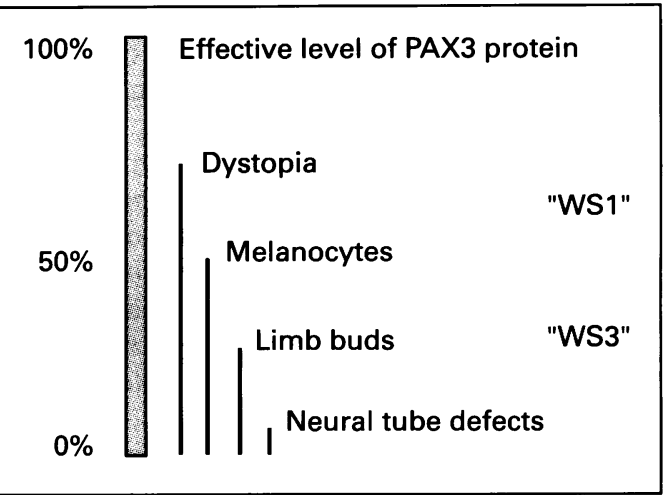

Figure $5 A$ hypothesis to explain PAX3 dosage effects. The effective level of PAX3 protein depends both on the amount of functional $P A X 3$ protein and on variations in the cellular systems that respond to PAX3 signalling.

Dystopia canthorum is always seen when $P A X 3$ dosage is reduced, melanocyte defects are common in people with $50 \%$ dosage, limb defects (WS3) are seen only in heterozygotes who have relatively inefficient $P A X 3$ response systems, or in people homozygous for loss of function PAX3 mutations.

tify the DNA targets to which the PAX3 protein binds. Optimal binding sites for PAX 3 protein in vitro have been determined by repeated cycles of immunoprecipitation and PCR of panels of random oligonucleotides. For the paired domain optimal binding was achieved with the oligonucleotide CGTCACG(G/C)TT, ${ }^{42}$ and for the homeodomain (of the Drosophila paired protein) CCTGAGTCTAATTGATTACTGTACAG. ${ }^{43}$

Within these longer sequences, consensus core binding sequences of GTTCC or GTTAC (paired domain) and ATTA (homeodomain) have been recognised. ${ }^{44}$

It is worth reflecting, however, that master switches in development probably depend on low affinity interactions. Downstream of the master genes, the effector mechanisms need high affinity binding to make them specific and reliable. However, the master switch, the decision point that sends only some of a population of cells down a certain developmental pathway, needs a finely balanced affinity to work. As with haemoglobin and oxygen, binding that is too strong is just as bad as binding that is too weak. Thus, the natural targets may be deliberately non-optimal. Most in vitro studies of PAX3 DNA binding have used the e5 sequence from the promoter of the Drosophila even-skipped gene; however, it should be noted that Drosophila mutants deficient in prd, or ectopically expressing prd, show no changes in even-skipped regulation. ${ }^{45}$ To date, only one natural target of PAX3 is known, the MET oncogene. ${ }^{42}$

Over 50 different PAX 3 mutations have been described in patients with WS1 or WS3. Fig 4A summarises mutations detected by our group $^{10} 354647$ (unpublished data). Others have reported similar findings. ${ }^{36}{ }^{48-53}$ The mutations are almost always different in different affected families; the only mutations seen in more than one family are 874ins(G) which inserts a seventh $G$ into a run of six Gs, and substitutions of R270 or R271 attributable to deamination of $\mathrm{CpG}$. Mutations fall into three classes.

(1) Deletions, frameshifts, splice site mutations, or nonsense mutations that are expected 
to act as null alleles. These include complete deletion of the PAX3 gene. Mutations in this class are scattered across exons 2-6 of the PAX 3 gene, though in contrast to PAX6 (and for unknown reasons), they are rare in the $3^{\prime}$ part of the gene.

(2) Amino acid substitutions in the 5' part of the paired box. These all affect amino acids known to make important DNA contacts in the prd-DNA complex. ${ }^{54}$

(3) Amino acid substitutions in the third alpha helix of the homeodomain. This helix (the recognition helix) is known to be critical for recognition by homeodomain proteins of their DNA target. ${ }^{55}$

These findings suggest that the mutational mechanism is loss of function and that the pathogenesis of WS1 depends on haploinsufficiency. We favour the model in fig 5 . Development of the frontal bone must be uniquely sensitive to $\mathrm{PAX} 3$ dosage, so that it is virtually always disturbed by loss of function mutations in PAX3. Differentiation and survival of melanocytes is less sensitive, so that pigmentary changes and hearing loss are much more variable features of the syndrome. Development of limb buds is relatively insensitive to PAX3 dosage and is normally disturbed only in homozygotes. Occasional heterozygotes, however, do show signs of limb involvement, usually minor, and these are the mild WS3 patients discussed below. The effect of reduced PAX3 protein level could be milder or more severe, depending on variations in the unknown protein or DNA targets of PAX 3 action in development. These are the modifier genes for PAX3 effects.

In general there is no clear correlation between genotype and phenotype in WS1. The symptoms are very variable even within families, which is perhaps only to be expected if the mechanism is haploinsufficiency; genetic background will have important modifying effects. However, mutation of asparagine 47 in the paired domain of PAX3 might have a special effect. Two families have been described that have atypically severe phenotypes segregating with mutations at this site. In the only known family with more than one case of WS $3,{ }^{56}$ four affected members have the mutation $\mathrm{N} 47 \mathrm{H},{ }^{48}$ while a small family having a phenotype described as craniofacial-deafness-hand syndrome (MIM 122880) have the mutation N47K. ${ }^{57}$ The three affected people in this family all have sensorineural hearing loss, dystopia canthorum, flexion contractures of the fingers, and an almost complete absence of nasal bones, but no pigmentary disturbances.

\section{MITF and Waardenburg syndrome type \\ II}

Hughes et $a f^{8}$ mapped the mutation in one large WS2 family to $3 \mathrm{p} 12-\mathrm{p} 14$. At the same time, Tachibana et a ${ }^{9}$ mapped MITF, the human homologue of the mouse microphthalmia gene to the same location. Microphthalmia had long been seen as a good candidate homologue for WS ${ }^{60}$ and mutations in MITF were soon found in several WS2 families. ${ }^{61}$
MITF and its mouse homologue $m i$ encode proteins belonging to the well known family of b-HLH-Zip (basic helix-loop-helix leucine zipper) transcription factors. These proteins dimerise as homo- or heterodimers through their HLH-Zip regions and bind DNA through their basic regions. Mi/MITF is one of the few loci at which more alleles and a richer molecular pathology have been found in mice than in man. Mutations in the basic region generally produce molecules that can cause dominant negative effects by sequestering wild type molecules in dimers that cannot bind DNA correctly. Mice heterozygous for these mutations have white spotting or, in some cases, dilution of the coat colour. Homozygotes for these, or for the recessive alleles with dimerisation defects, are mainly or entirely white, and some alleles produce microphthalmia, mast cell defects, osteopetrosis, or dental defects. Compound heterozygotes sometimes have phenotypes unexpectedly more severe or less severe than expected on this model. The mi protein dimer has been shown to bind to a DNA sequence AGTCATGTGCT (the $M$ box) found upstream of several melanocyte specific genes. ${ }^{62}$ The CATGTG core of this sequence is a target for binding by several b-HLH-ZIP proteins. Expression of $m i$ in mouse 3T3 fibroblasts can cause them to undergo melanocyte-like differentiation. ${ }^{63}$ It seems possible that $m i / M I T F$ is a master gene switching on melanocyte development, although it is also expressed in heart, and the phenotypes of some $m i$ mutants suggest additional functions.

In humans (fig 4B), MITF mutations have been found in a modest number of families with WS2, ${ }^{47616465}$ and in one family with the phenotype of Tietz-Smith syndrome. ${ }^{47}$ TietzSmith syndrome (MIM 103500) shows hearing loss combined with uniform non-patchy dilution of pigmentation; as mentioned above, some mi mouse mutants also show dilution rather than spotting. In the dominant families that attract the label of WS2, haploinsufficiency rather than a dominant negative effect seems the most likely pathogenic mechanism. ${ }^{47} 64$ The wide range of recessive phenotypes seen in mice prompted a search for MITF mutations in patients with severe recessive pigmentary syndromes, but so far none has been found. All the human families are dominant, and with the exception of the single Tietz-Smith family, all have typical WS2. Perhaps the incidence of hearing loss is rather higher than in non-MITF WS2 families, but it is not strikingly different, and we cannot predict which WS2 families will carry MITF mutations. MITF mutations have been found in only about $15 \%$ of families fitting the diagnostic criteria for WS2, and the major WS2 locus or loci remains to be found.

\section{PAX3 and Waardenburg syndrome type III}

WS3 remains something of an anomaly. Three rather separate combinations of auditorypigmentary symptoms with hypoplasia or contractures of the upper limbs can be seen. (1) Klein's original patient and the PAX3 homozy- 
gote of Zlotogora et $a l^{23}$ have profound hearing loss, depigmentation much more severe than in WS1, and a severe amyoplasia-like condition affecting the arms. (2) In the family reported by Sheffer and Zlotogora, ${ }^{56}$ people heterozygous for the PAX3 mutation $\mathrm{N} 47 \mathrm{H}$ have typical WS1 plus significant amyoplasia, inherited as a dominant condition. The amyoplasia is identical in pattern to that of Klein's patient, but less severe. (3) Finally, most cases labelled WS3 are sporadic or part of WS1 families, and have WS1 plus quite minor contractures of the elbows or fingers. Two cases we have tested are heterozygous for a $16 \mathrm{bp}$ deletion and a $1 \mathrm{bp}$ deletion, respectively, in the PAX3 gene, mutations typical of WS1.

\section{Endothelin 3, endothelin receptor B, and} Waardenburg syndrome type IV

Recent progress in identifying HSCR susceptibility genes has shed considerable light on WS4 and allowed a new definition of the syndrome. Patients with mutations in the endothelin 3 gene, EDN3, or the gene for its receptor, EDNRB, occasionally show a WS-HSCR phenotype, especially if homozygous. ${ }^{.6677576} \mathrm{Het}-$ erozygotes are usually unaffected or have isolated HSCR ${ }^{68-70}$ A family reported by Hofstra $e t a l^{1}$ is interesting: there is a pattern of low penetrance isolated deafness or pigmentary disturbances, resembling many families we have seen that do not quite meet criteria for WS2. In the family of Hofstra et $a l,{ }^{71}$ when cousins married they produced children with typical WS4 who were homozygous for an EDN3 mutation. However, we have sought EDN3 or EDNRB mutations in our families in vain (M Tassabehji, A P Read, unpublished data). They are certainly not a common cause of WS in the absence of HSCR. Some patients with chromosomal deletions or translocations affecting the sites of EDNRB at $13 \mathrm{q} 22$ or EDN3 at 20q13 have pigmentary disturbances without dystopia and with $^{72}$ or without ${ }^{73}$ HSCR. Mutations in other unidentified neural crest genes may also produce HSCR with pigmentary disturbances and maybe hearing loss, with or without dystopia. However, HSCR patients with RET mutations do not have melanocyte defects (M Seri, personal communication), nor probably do those with mutations in the RET ligand, GDNF.

\section{Conclusions and summary}

Research into Waardenburg syndrome provides some of the best examples of the interplay between mouse and human genetic research PAX 3 was investigated independently as a candidate gene for Splotch and Waardenburg syndrome on the basis of its map location in each species and expression pattern in the mouse. The mouse $m i, E d n r b$, and $E d n 3$ genes were each cloned when mice with random transgene insertions unexpectedly showed the phenotypes of microphthalmia, piebald lethal, and lethal spotting respectively. MITF and EDNRB then became positional candidates for the 3p14 linked WS2 and 13q linked WS4 respectively, while EDN3 was investigated as a pure (non-positional) candidate gene for WS4.
PAX3 and MITF illustrate how mutation analysis can help elucidate mechanisms of dominance. For PAX3 the evidence for haploinsufficiency is convincing, with the caveat that mutation of asparagine 47 may have some additional effect. For MITF the mechanisms are less certain, but it appears that here too haploinsufficiency is a major factor in producing the relatively mild abnormalities of WS2 among heterozygous mutation carriers. Dominant negative effects and pure recessive effects may also be found.

Clinically, the payoff from identifying the genes and characterising the mutations has so far been relatively modest. Diagnostic labels have been refined. WS1 and WS4 are now well defined genetic entities, while the label WS3 is largely redundant. WS2 remains a heterogeneous mix. Only a small proportion of type II families are accounted for by mutations in any of the genes defined so far. Moreover, the clinical definition of WS2 as a dominantly inherited patchy phenotype seems likely to exclude some patients with MITF mutations, for example, patients with dominant partial albinism of the Tietz-Smith type or with major recessive syndromes that include severe depigmentation. We can offer families an explanation of why they have Waardenburg syndrome, but we are still unable to predict what features of WS any particular PAX3, MITF, EDNRB, or EDN3 mutation will produce in a given person. Fortunately there is little interest in prenatal diagnosis among WS families. Nor is there much prospect for gene therapy, given that the abnormalities of WS arise in the early embryo.

Research into WS has allowed definition of transcription factors important in human embryonic development, not to mention finding the first homeobox gene to be implicated in a human inherited disease. PAX 3 and MITF between them exemplify three major families of transcription factors, the paired domain, homeodomain, and b-HLH-Zip proteins. Many questions remain, particularly about the precise developmental pathways in which these genes act, and the identity of modifier genes responsible for the highly variable expression in families. It was unexpected that defects in the EDN3-EDNRB system would produce developmental abnormalities, and the role of endothelins in development has yet to be elucidated. Auditory-pigmentary syndromes, as defects in cell differentiation, always promised to be biologically interesting, and research so far has amply borne out this promise.

We wish to thank May Tassabehji for her superb laboratory work, and members of the Waardenburg Consortium for sharing data and ideas. Our work was supported by the Hearing Research Trust and Wellcome Trust (grant 035301).

1 Waardenburg PJ. Dystopia punctorum lachrimarum blepharophimosis en partiele irisatrophie bij een doofstomme. Ned Tschr Geneeskd 1948;92:3463-5.

2 Waare aardenburg PJ. A new syndrome combining developmenpigme root with pigmentary defects of the iris and head hair and with congenital deafness. Am f Hum Genet 1951;3:195-253.

3 Arias S. Genetic heterogeneity in the Waardenburg syndrome. Birth Defects 1971;7(4):87-101.

4 Klein D. Historical background and evidence for dominan inheritance of the Klein-Waardenburg syndrome (type III) Am $\mathcal{F}$ Med Genet 1983;14:231-9. 
5 Shah KN, Dalal SJ, Sheth PN, Joshi NC, Ambani LM. White forelock, pigmentary disorder of the irides and long
segment Hirschsprung disease: possible variant of segment Hirschsprung disease: possible variar

6 Liu XZ, Newton VE, Read AP. Waardenburg syndrome type 2: phenotypic findings and diagnostic criteria. $\mathrm{Am} \mathcal{F} \mathrm{Med}$ Genet 1995;55:95-100.

7 Fraser GR. The causes of profound deafness in childhood Baltimore: Johns Hopkins University Press, 1976

8 Arias S, Mota M. Apparent non-penetrance for dystopia in Waardenburg syndrome type 1 with some hints on the diagnosis of dystopia canthorum. $\mathcal{F}$ Genet Hum 1978;26: 101-31.

9 Newton VE. Waardenburg's syndrome: a comparison of biometric indices used to diagnose lateral displacement of the inner canthi. Scand Audiol 1989;18:221-3.

10 Tassabehji M, Read AP, Newton VE, et al. Mutations in the PAX3 gene causing Waardenburg syndrome type 1 and type 2. Nat Genet 1993;3:26-30.

11 Fisch L. Deafness as part of an hereditary syndrome. $f$ Laryngol Otol 1959;73:355-82.

12 Delleman JW, Hageman MJ. Ophthalmological findings in 34 patients with Waardenburg syndrome. $f$ Paediat Ophthalmol Strab 1978;15:341-5.

13 Goldberg MF. Waardenburg's syndrome with fundus and other abnormalities. Arch Ophthalmol 1966;76:797-809.

14 Reed WB, Stone VM, Boder E, Ziprkowski L. Pigmentary disorders in association

15 Di George AM, Olmsted RW, Harley RD. Waardenburg's syndrome. F Pediatr 1960;57:649-69.

16 Farrer LA, Grundfast KM, Amos J, et al. Waardenburg syndrome (WS) type 1 is caused by defects at multiple loci, one of which is near ALPP on chromosome 2: first repor of the WS Consortium. Am f Hum Genet 1992;50:902-13.

17 Hageman M, Delleman J. Heterogeneity in Waardenburg syndrome. Am ₹ Hum Genet 1977;29:468-85.

18 Newton VE. Hearing loss and Waardenburg syndrome: implications for genetic counselling. $\mathcal{f}$ Laryngol Otol 1990 104:97-103.

19 Nemansky J, Hageman MJ. Tomographic findings of the inner ears of 24 patients with Waardenburg's syndrome. $A$ FR 1975;124:250-5.

20 da-Silva EO. Waardenburg I syndrome: a clinical and genetic study of two large Brazilian kindreds, and literature review. Am f Med Genet 1991;40:65-74.

21 Pantke OA, Cohen MM. The Waardenburg syndrome. Birth Defects 1971;7(7):147-52.

22 Giacola JP, Klein SW. Waardenburg's syndrome with bilateral cleft lip. Am ₹ Dis Child 1969;117:344-8.

23 Zlotogora J, Lerer I, Bar-David S, Ergaz Z, Abielovich D. Homozygosity for Waardenburg syndrome. Am $f$ Hum Genet 1995;56:1173-8.

24 Aymé S, Philip N. Possible homozygous Waardenburg syndrome in a fetus with exencephaly. Am $\mathcal{F}$ Med Genet 1995 59:263-5.

25 Hultén $\dot{M}$, Honeyman MM, Mayne AJ, Tarlow MJ. Homozygosity in piebald trait. $\mathcal{f}$ Med Genet 1987;24:568 71

26 Steel KP, Bock GR. Hereditary inner-ear abnormalities in animals. Arch Otolaryngol 1983;109:22-9.

27 Steel KP, Barkway C. Another role for melanocytes: their importance for normal stria vascularis development in the mammalian inner ear. Development 1989;107:453-63.

28 Hearing VJ. Unraveling the melanocyte. Am $\mathcal{f}$ Hum Genet 1993;52:1-7.

29 Barsh GS. Pigmentation, pleiotropy, and genetic pathway in humans and mice. Am 7 Hum Genet 1995;57:743-7.

30 Foy C, Newton VE, Wellesley D, Harris R, Read AP. Assignment of WS1 locus to human 2 q37 and possible homology between Waardenburg syndrome and th Splotch mouse. Am f Hum Genet 1990;46:1017-23.

31 Ishikiriyama $\mathrm{S}$, Tonoki $\mathrm{H}$, Shibuya $\mathrm{Y}$, et al. Waardenbur syndrome type $I$ in a child with de novo inversion (2) (q35q37.3). Am ₹ Med Genet 1989;33:505-7.

32 Martin D, Tucker DF, Gorman P, Sheer D, Spurr NK Trowsdale J. The human alkaline phosphatase gene and related sequences map to chromosome 2 band 2q37. Ann Hum Genet 1987;51:145-52.

33 Tsukamoto $\mathrm{K}$, Tohma T, Ohta $\mathrm{T}$, et al. Cloning and characterization of the inversion breakpoint at chromosome $2 \mathrm{q} 35$ in a patient with Waardenburg syndrome type 1 . Hum Mol in a patient with Waarde

34 Epstein DJ, Vekemans M, Gros P. Splotch (Sp2H), a mutathe mouse neural tube, shows a deletion within the paired homeodomain of Pax-3. Cell 1991;67:767-74.

35 Tassabehji M, Read AP, Newton VE, et al. Waardenburg syndrome patients have mutations in the human homologue of the Pax-3 paired box gene. Nature 1992;355:635 6.

36 Baldwin CT, Hoth CF, Amos JA, da-Silva EO, Milunsky A An exonic mutation in the HuP2 paired domain gen causes Waardenburg's syndrome. Nature 1992;355:637-8.

37 Goulding $\mathrm{MD}$, Chalepakis G, Deutsch U, Erselius JR Gruss P. Pax-3, a novel murine DNA-binding protein expressed during early neurogenesis. EMBO f 1991;10: 1135-47.

38 Gruss P, Walther C. Pax in development. Cell 1992;69:719 22.

39 Stuart ET, Kioussi C, Gruss P. Mammalian PAX genes. Annu Rev Genet 1994;28:219-36.

40 Gerard M, Abitbol M, Delezoide AL, Dufier JL, Mallet J, Vekemans $M$. PAX-genes expression during human embryonic development, a preliminary report. $C R$ Acad Sci Paris 1995;318:57-66.

41 Bober E, Franz T, Arnold HH, Gruss P, Tremblay P. Pax-3 is required for the development of limb muscles: a possible role for migration of dermomyotomal muscle progenitor cells. Development 1994;120:603-12.

42 Epstein JA, Shapiro DN, Cheng J, Lam PYP, Maas RL. Pax 3 modulates expression of the c-Met receptor during limb muscle development. Proc Natl Acad Sci USA 1996;93:4213-18.

43 Underhill DA, Vogan KJ, Gros P. Analysis of the mouse Splotch-delayed mutation indicates that the $\mathrm{Pax}-3$ paired domain can influence homeodomain DNA-binding activity. Proc Natl Acad Sci USA 1995;92:3692-6.

44 Chalepakis G, Jones FS, Edelman GM, Gruss P. Pax-3 contains domains for transcription activation and transcription inhibition. Proc Natl Acad Sci USA 1994;91:12745-9.

45 Epstein JA, Cai J, Glaser T, Jepeal L, Maas R. Identification of a Pax paired domain recognition sequence and evidence of a Pax paired domain recognition sequence and evidence for DNA-dependent

46 Tassabehji M, Newton VE, Leverton $\mathrm{K}$, et al. PAX3 gene structure and mutations: close analogies between Waardenburg syndrome type 1 and the Splotch mouse. Hum Mol Genet 1994;3:1069-74.

47 Tassabehji M, Newton VE, Liu XZ, et al. The mutational spectrum in Waardenburg syndrome. Hum Mol Genet 1995;4:2131-7.

48 Hoth CF, Milunsky A, Lipsky N, Sheffer R, Clarren SK, Baldwin CT. Mutations in the paired domain of the human PAX3 gene cause Klein-Waardenburg syndrome (WS-III) as well as Waardenburg syndrome type 1 (WS-1). $A m$ f Hum Genet 1993;52:455-62.

49 Baldwin CT, Hoth CF, Macina RA, Milunsky A. Mutations in PAX 3 that cause Waardenburg syndrome type 1 : ten new mutations and review of the literature. Am $f$ Med Genet 1995; 58:115-22.

50 Morell R, Friedman TB, Moeljopawiro S, Hartono, Soewito, Asher JH. A frameshift mutation in the HuP2 paired domain of the probable human homolog of murine Pax-3 is responsible for Waardenburg syndrome type 1 in an Indonesian family. Hum Mol Genet 1992;1:243-7.

51 Morell R, Carey ML, Lalwani AK, Friedman TB, Asher JH. Three mutations in the paired homeodomain of PAX 3 that cause Waardenburg syndrome type 1. Hum Hered 1997;47: 38-41.

52 Lalwani AK, Brister JR, Fex J, et al. Further elucidation of the structure of PAX3, and identification of two different point mutations within the PAX 3 homeobox that cause Waardenburg syndrome type 1 in two families. Am F Hum Genet 1995;56:75-83.

53 Butt J, Greenberg J, Winship I, Sellars S, Beighton P, Ramesar $R$. A splice junction mutation in PAX 3 causes Waardenburg syndrome in a South African family. Hum Mol Genet 1994;3:197-8.

54 Xu W, Rould MA, Jun S, Desplan C, Pabo CO. Crystal structure of a paired domain-DNA complex at $2.5 \mathrm{~A}$ resolution reveals structural basis for Pax developmental mutations. Cell 1995;80:639-50.

55 Kissinger CR, Liu B, Martin-Blanco B, Kornberg TB, Pabo CO. Crystal structure of an engrailed homeodomain-DNA complex at 2.8A resolution: a framework for understanding homeodomain-DNA interactions. Cell 1990;63:579-90.

56 Sheffer R, Zlotogora J. Autosomal dominant inheritance of Klein-Waardenburg syndrome. Am $\mathcal{F}$ Med Genet 1992;42: 320-2.

57 Asher JH, Sommer A, Morell R, Friedman TB. Missense mutation in the paired domain of $P A X 3$ causes mutation in the paired domain of PAX3 causes craniofa

58 Hughes A, Newton VE, Liu XZ, Read AP. A gene for Waardenburg syndrome type 2 maps to human chromosome 3p12-p14.1. Nat Genet 1994;7:509-12.

59 Tachibana M, Perez-Jurado LA, Nakayama A, et al. Cloning of MITF, the human homolog of the mouse microphthalmia gene and assignment to chromosome 3p14.1-p12.3. Hum Mol Genet 1994;3:553-7.

60 Asher JH, Friedman TB. Mouse and hamster mutants as models for Waardenburg syndrome in humans. $f \mathrm{Med}$ Genet 1990;27:618-26.

61 Tassabehji M, Newton VE, Read AP. Waardenburg syndrome type 2 caused by mutations in the human microphthalmia (MITF) gene. Nat Genet 1994;8:251-5.

62 Hemesath TJ, Steingrimsson E, McGill G, et al. Microph thalmia, a critical factor in melanocyte development, thalmia, a critical factor in melanocyte development, 1994;8:2770-80.

63 Tachibana $M$. Takeda $K$, Nobokuni $Y$, et al. Ectopic expression of $M I T F$, a gene for Waardenburg syndrome type 2 , converts fibroblasts to cells with melanocyte characteristics. Nat Genet 1996;14:50-4.

64 Nokuni Y, W/ana $M$. Analyses of loss-of-function mutations of the MITF gene suggest that haploinsufficiency is a cause of Waardenburg syndrome type 2a. Am f Hum Genet 1996;59:76-83.

65 Morell R, Spritz RA, Ho L, et al. Apparent digenic inheritance of Waardenburg syndrome type 2 (WS2) and autosomal recessive ocular albinism (AROA). Hum Mol Genet 1997;6:659-64.

66 Puffenberger EG, Hosoda K, Washington SS, et al. A missense mutation of the endothelin-B receptor gene in multigenic Hirschsprung's disease. Cell 1994;79:1257-66.

67 Chakravarti A. Endothelin receptor-mediated signaling in Hirschsprung disease. Hum Mol Genet 1996;5:303-8. 
68 Kusafuka T, Wang Y, Puri P. Novel mutations of the endothelin $\mathbf{B}$ receptor gene in isolated patients the endothelin B receptor gene in isolated patients with 9 .

69 Auricchio A, Casari G, Staiano A, Ballabio A. Endothelin-B receptor mutations in patients with isolated Hirschsprung disease from a non-inbred population. Hum Mol Genet 1996;5:351-4.

70 Amiel J, Attie T, Jan D, et al. Heterozygous endothelin receptor $B$ (EDNRB) mutations in isolated Hirschsprung disease. Hum Mol Genet 1996;5:355-7.

71 Hofstra RM, Osinga J, Tan-Sindhunata G, et al. A homozygous mutation in the endothelin-3 gene associated with a combined Waardenburg type 2 and Hirschsprung phenotype (Shah-Waardenburg syndrome). Nat Genet 1996;12:445-7.
72 Hood OJ, Doyle M, Hebert AA, Oelberg DG. Association of Waardenburg syndrome type II and a de novo balanced 7;20 Waardenburg syndrome type II and a de novo balanced

translocation. Dysmorphol Clin Genet 1989;3:122-3.
73 Van Camp G, Van Thienen MN, Handig I, et al. Chromosome 13q deletion with Waardenburg syndrome: further evidence for a gene involved in neural crest function on 13q. F Med Genet 1995;32:531-6.

74 Nakashima S, Sando I, Takahashi H, Hashida Y. Temporal bone histopathologic findings of Waardenburg's syndrome: a case report. Laryngoscope 1992;102;563-7.

75 Attié T, Till M, Pelet A, et al. Mutation of the endothelin-receptor B gene in Waardenburg-Hirschsprung disease. Hum Mol Genet 1995;4;2407-9.

76 Edery P, Attié T, Amiel J, et al. Mutation of the endothelin-3 gene in the Waardenburg-Hirschsprung disease (ShahWaardenburg syndrome). Nat Genet 1996;12:442-4. 